\title{
Visual Design in Distance Education
}

By David Kaufman, Saeko Usukawa
and Denise Sketthes

This paper provides a brief overview of The visual design process is then des-
cribed and examples are given of several cribed and examples are given of several
different approaches used to generate different approaches used to generate
visual ideas. Finally, a two-dimensional model is given for classifying visuals according to the function (instructional,
motivational and directional) and mode motivational and directional) and mode
(drawing or photograph). Examples are then given of visuals in both modes
created at the Institute which fulfil various functions.

Establishment of the Open

Learning Institute

The Open Learning Institute [OLI] is relatively new, public, distance educatio institution in Canada. It was established
by the British Columbia Provincial Government in June 1978. The Institute has a broad and challenging mandate to perform the following functions:
(1) (a) provide programs of study

(a) provide programs of study
leading to a first degree in Arts and Science;
ant degree in Arts (b) provide programs of study in
career, technical and vocational areas and; adult basic

(2) The Institute shall manage needed support services, develop and
acquire courses, programs of study nd learning materials and distribmethods.
my distance education Many definitions have been given for the term "Distance Education". In this tional process in which a significant someone removed in space and/or tim from the learner. The purpose of the Instate is to provide these services to amongst others, geographically or socially
isolated adults across the Province of British Columbia.

It should be pointed out that the Instcontext of distance

David Kaufman is currently the
Director of Educational Technology at the Open Learning Institute of British Colum bia. He is examining the role of com minications and computer technology in distance education. He did his
undergraduate and masters work in elecundergraduate and masters work in erec
trical engineering at McGill University before entering the field of education i which he completed his doctorate in 1973
at the University of British Columbia.

\section{TABLE 1}

Status of the Institute, January, 1982

Enrolments

- September 1979 - 750 enrolments

- January $1980=2,400$

- 11,000 (predicted

Students

- Two-thirds are between ages 25-40.

- Two-thirds are women.

Courses Available

Most developed
in-house)

- September 1979 - 7 credit courses

- January $1980-37$

- January $1981=64$

Programs

Adult Basic Education: Grade X completion; Grade XII completion.

- Career/Technical/Vocational: Nine certificate$$
\text { programs: }
$$

- General -Office Managemen

- Construction Management - Secretarial

$\begin{array}{ll}\text { - Industrial Supervision } & \text { - Electronics } \\ \text { - Motel Management } & \text { - Restaurant } \\ & \end{array}$

- University: Bachelor's Degree: Eight academic

$\begin{array}{ll}\text { - Economics } & \text { - Sociology } \\ \text { - History } & \text { - Geography } \\ \text { - Psychology } & \text { - Mathematics }\end{array}$

$\begin{array}{ll}\text { - Psychology } & \text { - Mathematics } \\ \text { - English } & \text { - Biology }\end{array}$

Student Support Services - Seven Regional Advising Centres throughou British Columbia

ch course, mail and toll-free

- Library "hot-line"

Staff

- 106 regular and 23 temporary employees

- (in-house)

and consultants

Seko Usukawa is editor with Douglas and McIntyre, a Canadian publisher in formerly a course designer at the Open Learning Institute of British Columbia

and specialized in the design of technic
and adult basic education materials. Denise Sketches in a visual designer a umbia and is particularly interitish Cot use of visuals to aid learning. She has an associate arts diploma in graphic and communicative arts from Douglas Colleg (B.C.) and has recently completed ducation projects existing in Canada an to niversitê, North Island College, and the University of Waterloo Correspondence institution is The Open University in $\mathrm{Br}$ ain. Other notable institutions includ Everyman University in Israel and the States.

Current status of the Institute

Table 1 provides a summary of the nuary 1981. It is clear from these data that the Institute has grown very rapidly since its inception.

It establishment of its current status have been described earlier (Mugridge, 1981).

Components of an OLI Course

Package

OLI courses are paced home-study courses. Students are mailed packages hat contain all of the necessary ma eials package consists of a number of components, as shown in Figure 1. Some components are produced at the Open Learnis unlikely that all the components listed would be part of a particular course The majority of courses developed at the Open Learning Institute are based on provide the needed support to students for working through the textbook. A number of OLI courses are "stand-alone" courses. That is, they are seff-contained as the textbook in addition to the other functions outlined in Figure 1. For example, one OLI electricity course contains about 400 pages and 175 visuals. Since the major und to identify suitable published material. Course development at the

a course team approach. Each member of the team performs a particular function,
but often contributes ideas and expertise in several areas. This leads to carefully designed, developed and produced course materials which have benefited through
contributions by several individuals. The contributions by several individuals. The course team members and their functions a general way the course development process at the Institute.

Visual design at the Institute The visual design process at the Institute can be thought of as having two elements:

This paper deals mainly with the visua few words of visual design. However design.

Page Design

Page design refers to the particular configuration of text and visuals placed on the page. It includes decisions about typesize
and typefont, number of columns used and the width and depth of these columns. as well as size and placement of visuals. The outside and inside covers, copyrigh and acknowledgments page, and contents page also require their own particula

University courses use a Times Roman
typefont in 10 point while the Adult Basic Education and Career the Adult Basic tional areas use Univers Type in 12 point. three program areas make use of single column page layout is employed with large margins to accommodale visuals, actively researching page designs in order$$
\text { Tabre }
$$

TABLE 2

Main Function of Course Team Members

Course Team Member

Main Function

Course Writer

Consultan

Program-Co-Ordinator

Course Designer

Visual Designer

Copyright Officer

Pilot Student

(when available)

Scriptwriter and/or to expand its repertoire in the near future. Visual Support of Text Since June, 1979, more than 3,000 illusproduced at the Institute. Currently, more han 500 copyrighted photographs have been used (with permission) in OL been addressed as a result of these activities. What teaching role do these visual play in course materials? What are the enefits of using the course team ap visual design process function tot the InstiRole of visuals: The role that visuals play in course materials is a crucial issue for course designers and visual designers effective use and design of visuals is scarce. Holliday (1973) has concluded

Because of the complexity and almost infinite interrelationship ject content, presentation formats, and individual learner characteristics, specific prescriptions for (1) 
More recently, Broudy (1981) noted that
his examination of related literature revealed that there have been few atbetween pictures and learning from in structional texts. Nesbit's \{1981\} view is that the increased use of illustrations in on common sense guidelines and artistic notions than on experimental evidence. Duchastel (1980) concluded that research has had relatively little impact in the pra however that resartration. He did argue specific areas such as supporting the value of illustrations in assisting learnin (in a number of studies), showing tha proper use of illustrations He in the inthat the value of illustrations for motivational purposes must be accepted on in tuitive grounds-and not unreasonably
so. This particular view has been prevaso. This particular view has been preva-
lent at the Open Learning Institute during these early years of course development.
The assumption has been made that The assumption has been made that
visuals are inherently useful for instruc visuals are inherently useful for instruc-
tional as well as motivational purposes. Visual design process: At present, the
visual design process is primarily concerned with the design and development of visuals to support text material.

The prime responsibility for managing
the visual design process rests with the visual design process rests with the
course designer. The responsibility for controlling the creative design rests, of course, with the visual designer. The purpose of the design stage is to decide on the ticular course component (usually a unit. This stage usually involves input from several members of the course team. The development stage then involves illustration, photography or the acquisition of
visuals that were decided upon in the design stage.

The major benefit of using the course
design stage was team approach to visual design is that it instructional resources to produce instructionally valid and technically accurate visuals. The wide variety and scope of courses oflered by the Institute necesment of visuals. For instance the developrange from introductory to advanced
levels in science, humanities, technical and business courses. No two courses, . designed to be instructionally sound as weil as visually pleasing. The visual
design process often varies according to design process often varies according
the type of course. In a technical course such as electronics,
the type course the coursewriter usually initiates the
visuals. He or she is the subject area visuals. He or she is the subject area
specialist, knowing what the student has visual conventions of the particular subject or trade. In technical courses, the coursewriter first indicates or sketches
out rough comprehensive drawings of the lechnical information to be illustrated. course designer check, constlant and the proposed visuals. Once the proposed visuals are approved, they are passed on to the visual designer, who corrects and transforms the edited rough compreher is some latitude for cretivily in the manner of presentation, the visual designer must assure complete desig consistency throughout a course an In a humanities course such as psychology or sociology, the visual designer the manuscript or she reads hrough the manuscript and sugges are considered by other members of the course team. The visual designer may precher such as thumbnail sketch, a written these. The ideas for the visuals may be modified, adopted or dropped during discussion by the course team. Once the vourse team has approved the proposed ideas into finished visuals. Also, in man cases, permission is obtained for the use cen course. In many areas all members of the course team participate in the visual
design of the course. For instance, in a career course such as Business Management and Principles, the course team
often works together on the visual design. metimes the coursewriter may sugges concept that he or she wishes to $i$ of a very rough drawing or a written description. The visual designer then coniders the coursewriter's idea and renders more complete rough, which is the

Figure 1. Structure of an OLI course

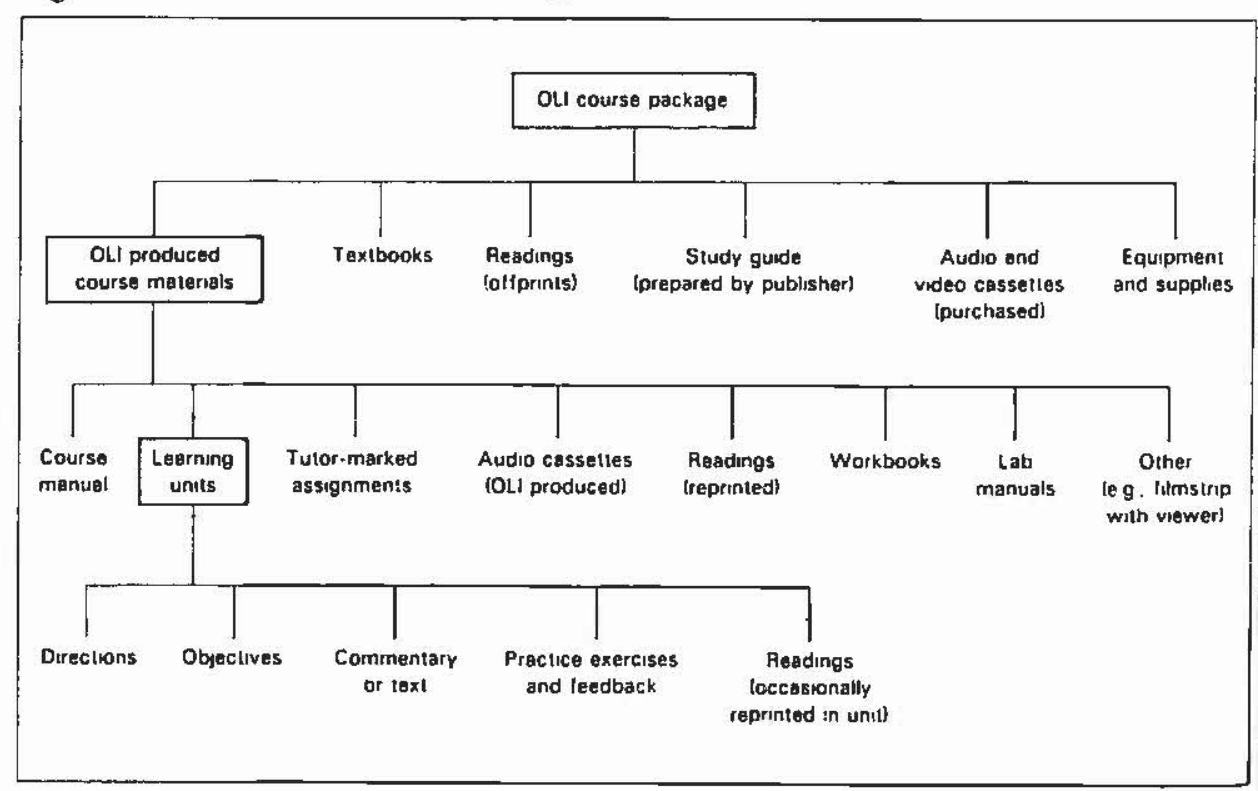

course team for discussion the ideas for visuals have been approve

visuals.
In summary, there are no clear rules for Learning Institute, but there are definit styles or approaches used. This flexibility has proven to be successful thus far in
maintaining the tenuous balance between creativity and productivity. two approaches used in the visual design
process at the Open Learning Inslitute. Classification of visuals

There have been several attempts a establishing frameworks for classifying
visuals. Knowlton (1966) provided a lead in this regard by classifying visuals as either realistic, analogical, or logical.
Twyman (1979) more recently proposed scheme that consists of a matrix with one
dimension describing the methods of consymbolization. Duchastel (1980) pointed out that there has been little enthusiasm
for these classification schemes, perhaps for these classification schemes, perhaps
because of difficulties of basing taxonomies on the physical attributes of visuals rather than their communicative intent. He suggested that it would be
more useful to use a functional approach more useful to use a functional approach
to classifying visuals. This approach is primarily concerned with the function of a visual, while the appearance of a visual is of secondary concern. In his functional
scheme, illustrations are considered as having, attentional, explicative, and/or retentional roles. Duchastel more recently (1981) reported on a study from which he
concluded that illustrations can influence concluded that illusirations can influence retention even when they have no influ- pertinent theoretical elaborations and also developed a functional approach to research on visuals, play in text.
MacDonal

The examples in Figures 3 \& 4 illustrate. figuration of graphic language and the

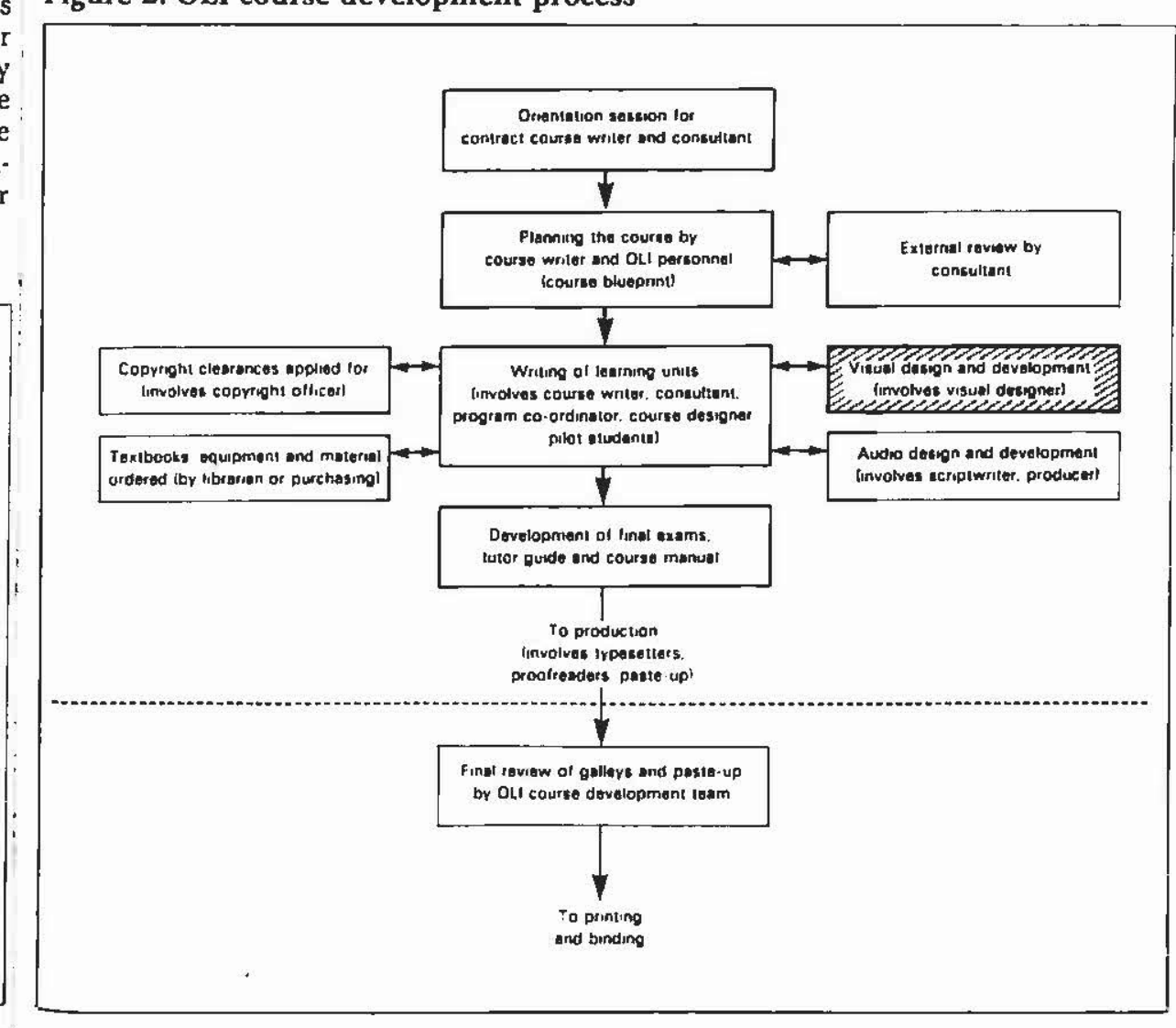

Motivational: To indirectly assist learn

classification schemes are useful in guiding research in this area. However,
they are also useful in indicating to the course team the various possibilities availthe visual medium. In order to examine the various types of
visuals used in OLI course material, we have classified them according to their purpose and mode. Figure $?$ shows the
scheme used for classifying visuals. Definitions of the terms used in the figure are then given.

Instructional: To assist learning by providing information in a visual
clarifying the text material. Iconic: To show what an object looks like,
and to identify and label key parts. Data Display: To display the results of

Explanatory: To show the logical relation-
ships between key ideas.

operational: To help the reader to perWright (1977) hant provided some usefu areas are better deveroped, guidelines pro-
vided by Wright and others have been particularly helpful in designing visuals or the lechnical and scientific courses
developed at the Institute. The present paper draws upon the work
of MacDonald-Ross (1977) who suggested a set of purposes that he thought could be

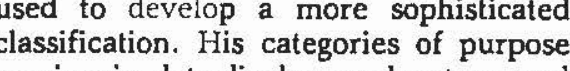
are: iconic, data display, explanatory, and operational. These categories form the
basis of the scheme suggested in the prebasis of the

Some diagrams have a single purpose,
but others combine two or more. Fo example, mathematical diagrams can be both explanatory and operational (algo
rithms); biological diagrams can be both iconic and explanatory (physiological diagrams); technical drawings can be both iconic a
diagrams!

r.

VOLUME 12, NUMBER 2, 1982 CANADIAN IOURNAL OE FDUCATIONAL COMMUNICATHON the text, e.g. cartoons, pictures of famo

people, pictorial settings. These visuals
help the subject matter to "come alive",

but are not intended to directly provide matter. Directional: To provide symbolic cues
which help guide the student through the text and supporting couse Mode

Mode refers to whether the visual is photograph. At the present time, the ma jority of illustrations are prepared by
visual designers at the Institute. Althoug the Institute shoots many of its ow
photographs, the majority of photographs
are copyrighted works obtained from out are copyrighted works obtained from out
side sources (with appropriate payment side sources (with appropriate paymen
and acknowledgement given). and acknowledgement given).
The following examples illustrate the two modes of visuals (illustrations an photographs) as they serve a number
purposes (instructional, motivational and

Examples of Visuals

An iconic visual /Figure 6/
This iconic visual is taken from a socia
studies course for grade 10 completion. "Consumer economics". This visual shows the student what a monthly revolving charge account statement looks like
In fact, it is a reproduction, reduced in size, of an actual charge account state
ment. The key parts of the statement ar
labelled and identified for the student.

A data display visual (Figure 7 )
This data display visual is taken from a
social studies course for grade 10 complesocial studies course for grade 10 comple-
tion. It is a graph showing the percentage tion. It is a graph showing the percentages
of hidden taxes in the pump price of gasoline. Notice that the graph is in the esting way to present this type of data to a student at this level. This same informa-
tion in a more conventional table or graph would not be as attention-getting or as memorable.

An explanatory visual and a directiona This explanatory visual shows the balanced relationship between the body intake and loss of water. It also shows the
factors involved in intake and loss. Note the directional visual that appears in the left-hand margin. This particular directional visual alerts the student to do part
of an assignment. The Open Learning Institute has developed a library of direc dent to experiments, audiotapes, readings, etc. The learning unit it appears in is entitled 
a)

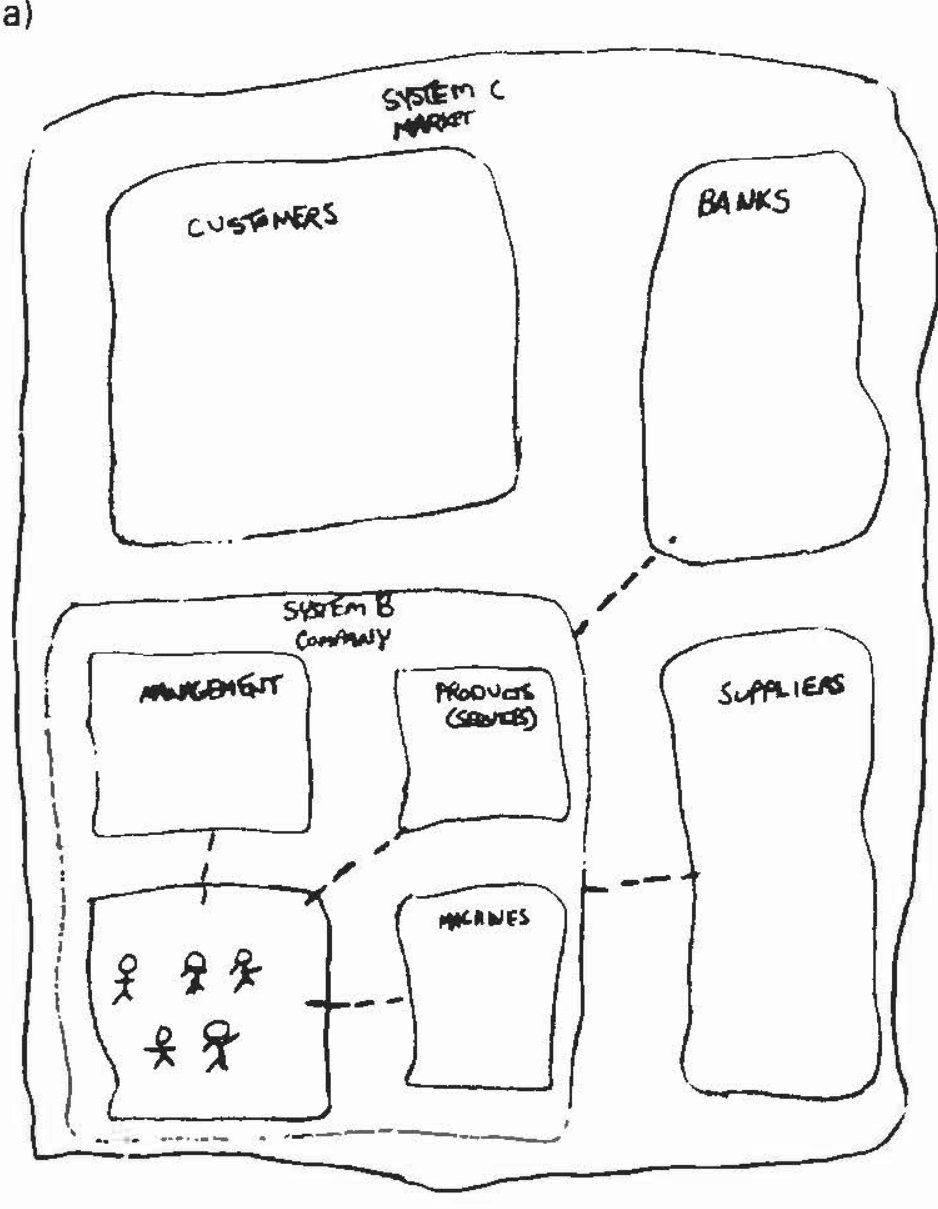

b)

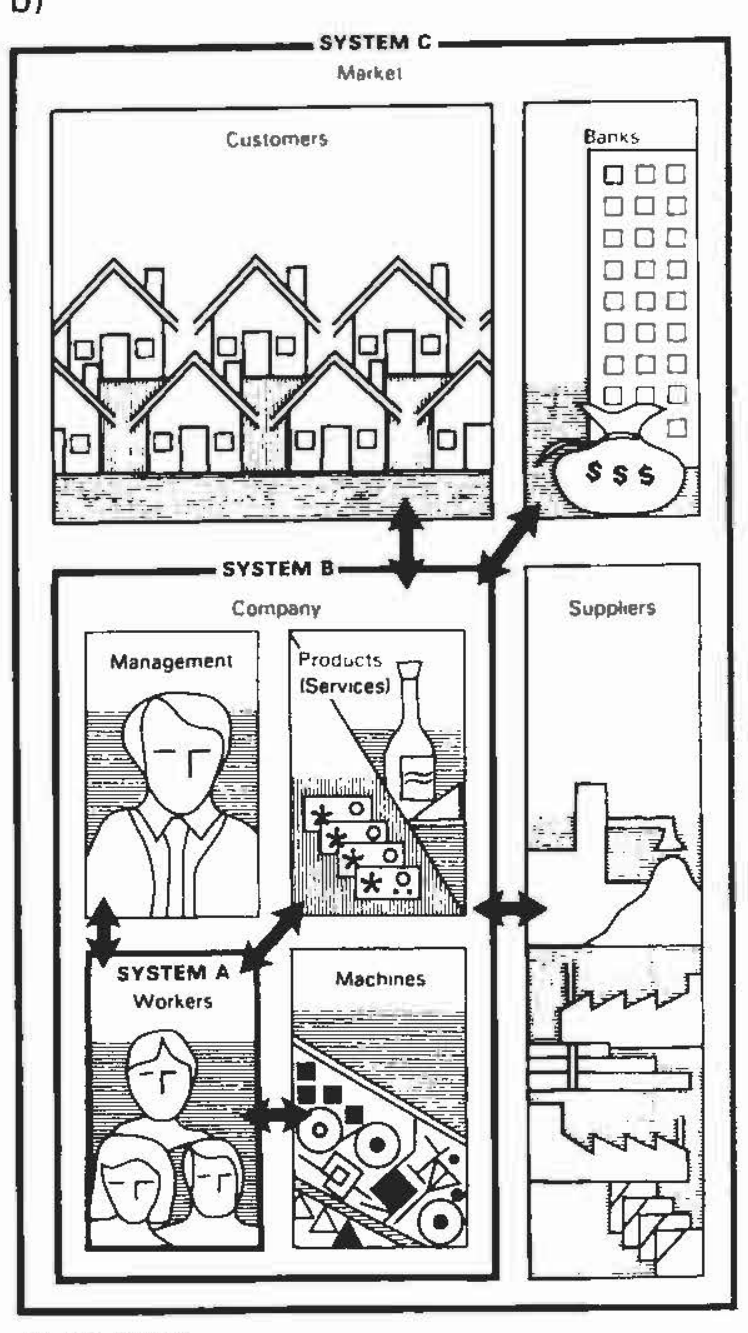

$F_{19}, 5$ Systems
"The visual designer read the coursewriter's manuscript and conceptualized a visual (Figure 4a) which later appeared in finished form in the leaming unit as shown in Figure $4 b$."

a)

or frustrated or anxious? (Maybe because it was a case it wasn't rea enough to bother you). Houever, most people in real life when faced with a hard decision get a "funny feeling" or anxiety uhich is called "dissonance". (Dissonance is theoncomfortable feeling which people expertence when no perfect solution exists for a problem and they must ' 5 choose an imperfect alternative. Remember the last time you made a major purchase, such as a house or car. If you had more than one alcernative did you try to weight the advantages and disadvantages of each? Did this only seem to make it harder to choose?

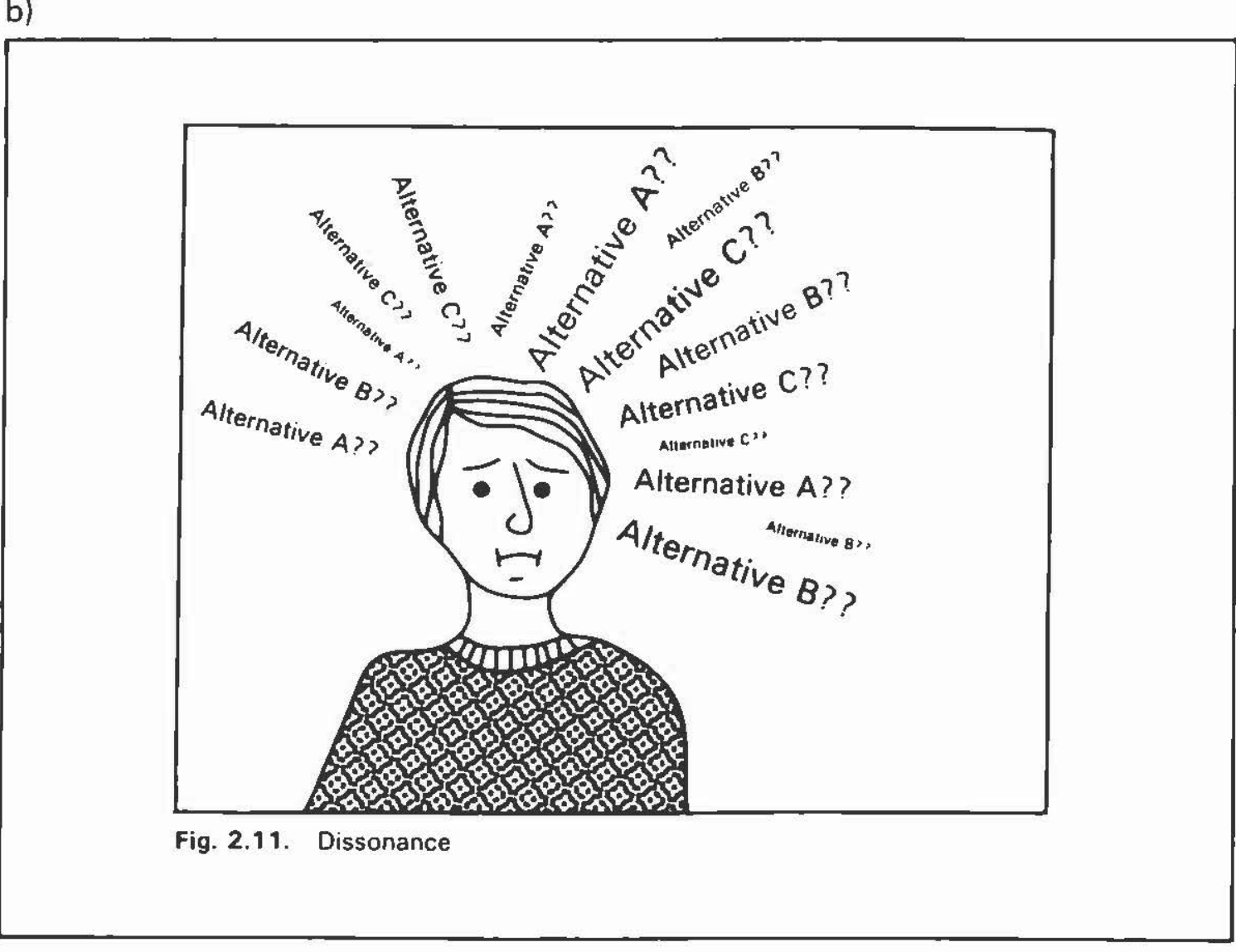



of the components involved. The lower visual is a cutaway illustration of the same operation involved in the phot rect positioning of the components in volved. the use of both modes make the operation very clear to the studen

A motivational visual (Figure 10) This motivational visual is taken from the cover of a university geography course. regions of Canada. Motivational visur are often used within courses as well as on the covers of learning units.

An iconic and operational visual (Figure 11 / This visual is taken from a basic business management course. The visual is both iconic and operational. It shows the transaction and the procedures to follow in accepting a cheque.

\section{Conclusions}

This paper has described the process of distance education Learning Institute, a newly created

Figure 5. Scheme for classifying visuals

\begin{tabular}{|c|c|c|c|c|}
\hline & \multicolumn{2}{|c|}{ MODE } \\
\hline & & & lllustrations & Photographs \\
\hline \multirow{6}{*}{ 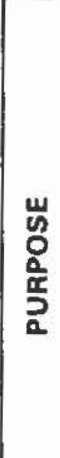 } & \multirow{4}{*}{ Instructional } & Iconic & & \\
\hline & & Data display & & \\
\hline & & Explanatory & & \\
\hline & & Operational & & \\
\hline & \multicolumn{2}{|l|}{ Motivational } & & \\
\hline & Directional & & & \\
\hline
\end{tabular}

Fleming, M. Classification and analysis munication Review, 1967, ion of the expertise of each mumber of team in a manner that pre serves the balance between creativity and productivity. The result of this process is therial which serves inse poses for the learner.

\section{REFERENCES}

Broudy, P.J. Research on pictures in Instructional texts: the need for a broad. . gal, 1981, 29/2) 93-100 - OgY Jour-

Duchastel, P. Illustrating instructiona 18(11), 36-39.

Duchastel, P. Research on illustrations in the text; issues and perspectives.
Educational Communication and
Technology Journal, 1980, 28, 83-287.

Duchastel, P. Textbook illustration: re search and instructional design. In Yearbook, 1980a, 58-63.

Duchastel, P. Illustrations in text: a reentional role. Programmed Learn ing and Education.
$1981,18(1), 11-45$.

Knowlton, J. On the definition of "pic lak6, 14, 157-183.

Levin J R On functions of pittres Paper No 801. Madison, Wis.: The University of Wis.

MacDonald-Ross, M. Graphics in texts. In L. Shulman (Ed.), Review of Re-

Mugridge, I. The establish ef a new 1981, 2(1), 98-109.

Nesbit, L.L. Eye appeal versus educatio. nal relevance in the selection of educagy, 1981, 21(1), 45-46.

Twyman, M. A scheme for the study of graphic language. In P. Kolers, M. Crolstad, and Hi. Baouma (Eds.), Pro. cessing of Visible Language (Vol. 1)
New York: Plenum, 1979.

Wright, P. Presenting technical informa in: a survey of research findings. 93-134.

1977. 6. tional, motivational and directional purconsin, Wisconsin R \& D. Later for distance education institution: The Open Learning Institute of British

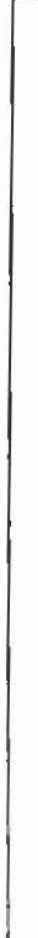

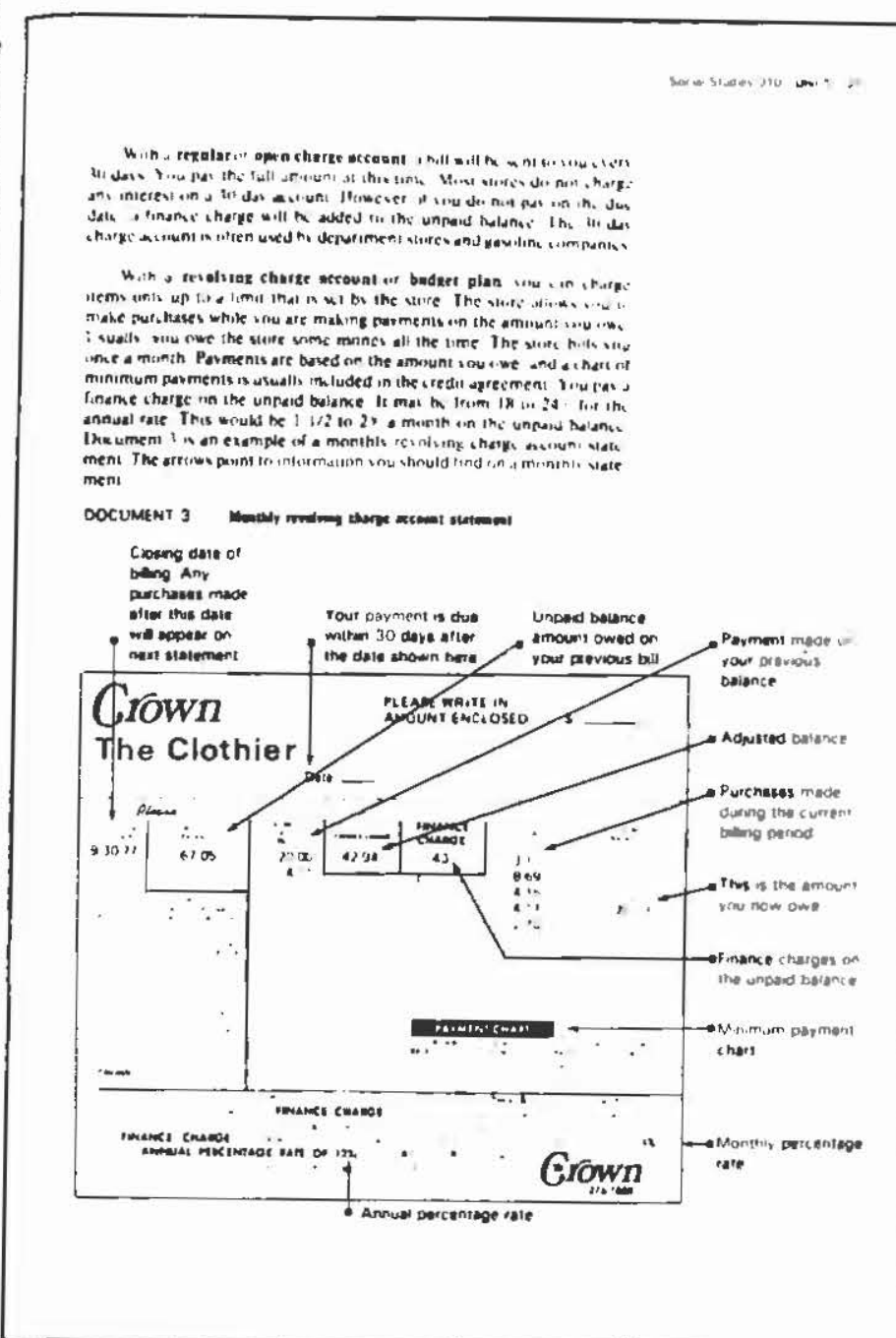

"This data display visual is taken from a social studies course for grade 10 completion. It is a graph showing the percentages of hidden taxes in the pump price of gasoline. Notice that the graph is in the shape of a gasoline pump. This is an interesting way to present this type of data to a student at this level. This same information in a more conventional table or graph would not be as attention-getting or as memorable."
"This iconic visual is taken from a social studies course for ed "Consumer economics". This unit it appears in is entit. what a monthly revolving charge account statement looks like. In fact, it is a reproduction, reduced in size, of an actual 作 labelled and identified for the student."

Figure 7. A data display visual

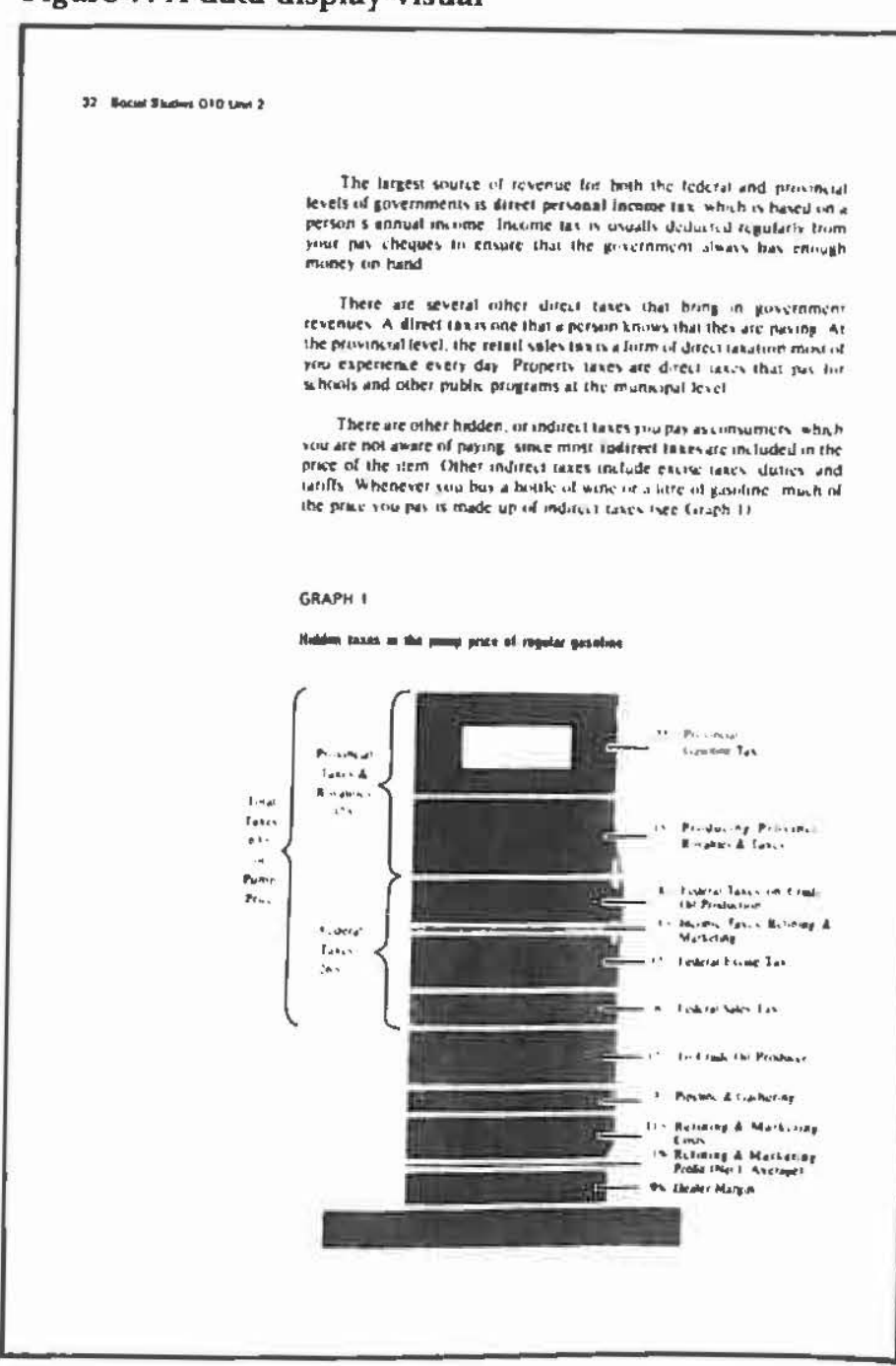


"The upper visual is a top-view photograph from a basic ing of the compons the student the correct positioncutaway illustration of the same operation invived in the photo in of the components involved. The use of both modes make

Figure 8. Explanatory and directional visuals (the directional visual is in the left-hand margin]

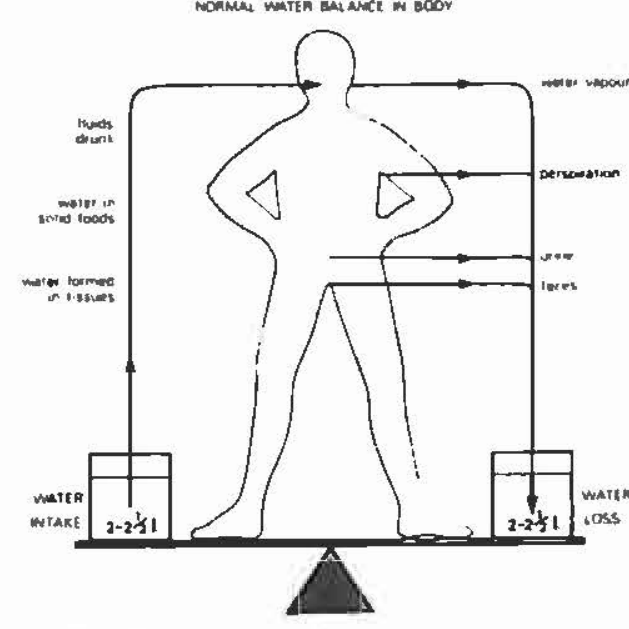

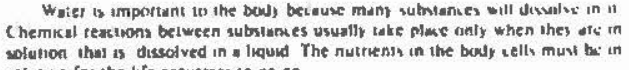

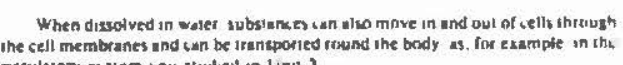

villy

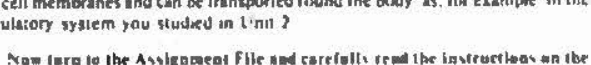

Food for control

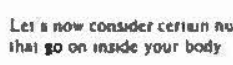

womang

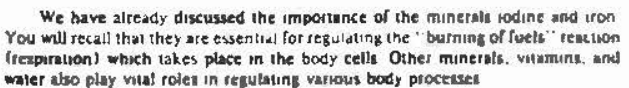

This explanatory visual shows the balanced relationship also shows the factors involved in intake and loss. Note the directional visual that appears in the left-hand margin. This particular directional visual alerts the student to do part of an assign ment. The Open Learning Institute has developed a library of directional visuals of this type, alerting the student to ex-

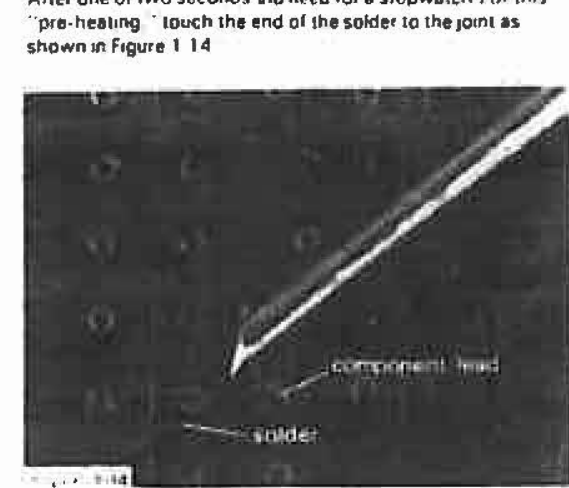

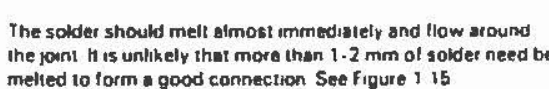

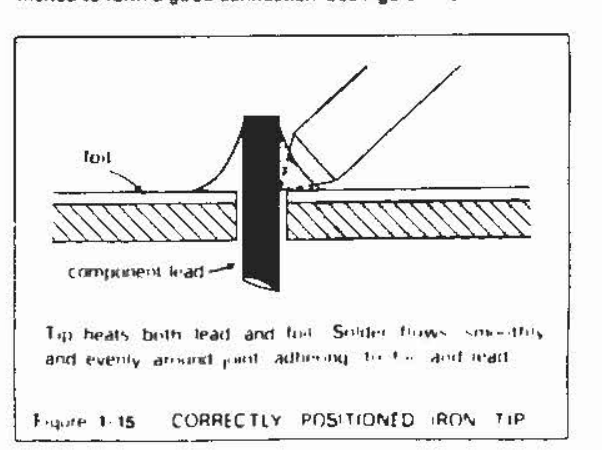

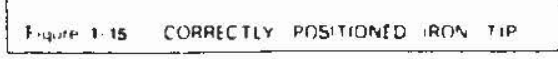

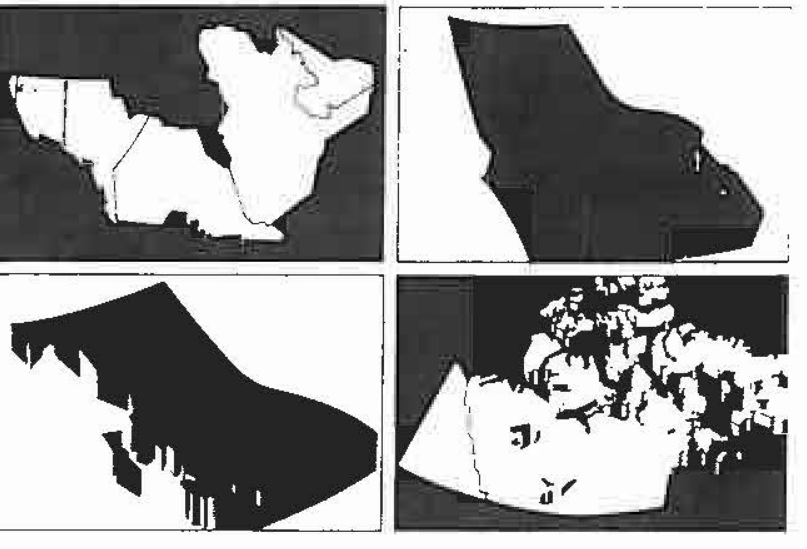

Course manual

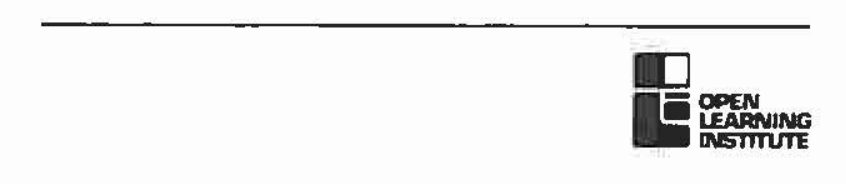

"This visual is taken from a basic business management course. The visual is both iconic and operational. It shows the key documents involved in a cheque transaction and the procedures to follow in accepting a cheque." view of the four within courses as well as on the covers of leaning units."

\section{4}

Figure 11. A visual that is dual-purpose, iconic and operational

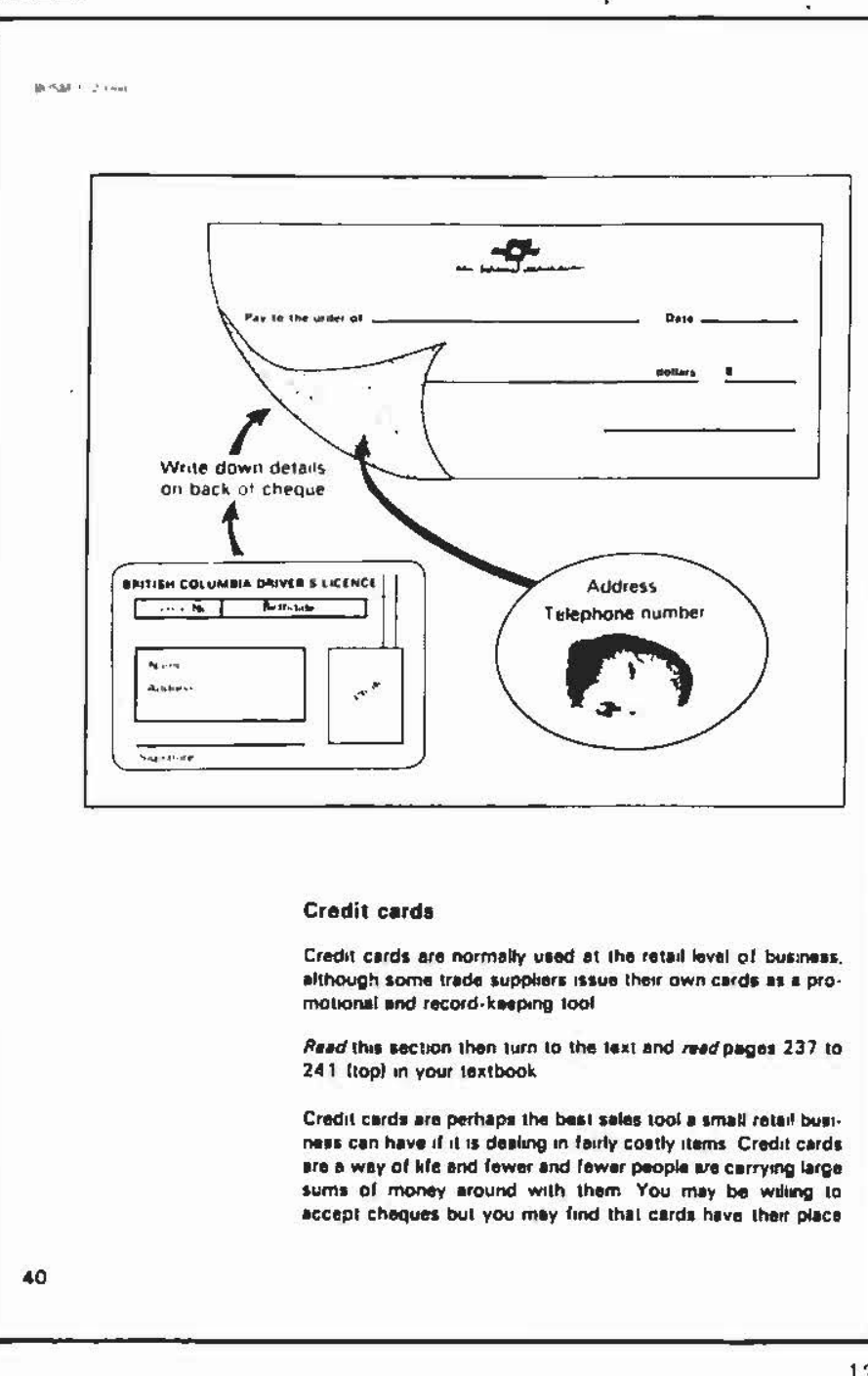

